\title{
Optimum Design of Reinforced Concrete T-Beam Considering Environmental Factors via Flower Pollination Algorithm
}

\author{
Aylin Ece Kayabekir ${ }^{a}$, Gebrail Bekdaş $^{b}$, Sinan Melih Nigdeli ${ }^{{ }^{*}}$ \\ ${ }^{a}$ Istanbul Gelişim University, Civil Engineering Department, 34310 Avcllar, Istanbul/Tukey \\ ${ }^{b, c}$ Istanbul University-Cerrahpaşa, Civil Engineering Department, 34320 Avcllar, Istanbul/Tukey \\ *E-mail address: melihnig@iuc.edu.tr \\ ORCID numbers of authors: \\ 0000-0003-3592-4564 ${ }^{a}, 0000-0002-7327-9810^{b}, 0000-0002-9517-7313^{c}$
}

Received date: 17.12 .2021

Accepted date: 29.12 .2021

\begin{abstract}
The minimum cost designs may be costly for the environment. In that case, the cost is not only a single objective in the design of structures. In that situation, $\mathrm{CO}_{2}$ emission minimization can be considered in the optimum design. In this study, reinforced concrete $(R C)$ T-beams were optimized via flower pollination algorithm for the environmental factor minimizing the $\mathrm{CO}_{2}$ emission of the materials. The investigation was done for 4 cases of $\mathrm{CO}_{2}$ emission values and these cases were compared with 5 cases of the cost ratios of concrete and steel. Due to this investigation, it was found that $\mathrm{CO}_{2}$ emission optimization is effective in the reduction of the $\mathrm{CO}_{2}$ emission value by $4.5 \%$ compared to cost optimization. If the ratios of $\mathrm{CO}_{2}$ emission and the cost of steel per concrete are different, the optimum design variables and objectives are different. Also, the use of recycled steel is \%.30.24 more effective on the reduction of $\mathrm{CO}_{2}$ emission and saving the planet.
\end{abstract}

Keywords: Metaheuristic; Carbon Minimization; Cost Optimization; Eco-friendly design; Minimum carbon emission.

\section{Introduction}

Due to a shortage of resources and sustainability, engineering design must be eco-friendly. In structural engineering, choosing eco-friendly or recycled material can play an important role. For the design of steel structures, the eco-friendliest material can be chosen, and it is optimum in minimization of $\mathrm{CO}_{2}$ emission if it has the same strength as the one with a higher emission value. Also, optimization can be done if the strengths are different for the steel types to find a design that has low $\mathrm{CO}_{2}$ emissions.

The optimization is more challenging for RC structures. For RC structures, two materials such as concrete and steel are used to provide a design in required ductility. These materials have different costs and different $\mathrm{CO}_{2}$ emissions. Also, the design is constrained by the factors given in design regulations. These problems can be only optimized via numerical iterations and the best way to apply numerical iteration systematically, effectively, and rapidly is through the usage of metaheuristic methods. 
To reach the optimum solution of RC members, various metaheuristic algorithms have been employed. The genetic algorithm that uses the factors such as mutation, crossover, reproduction [1-2] was used in the optimum design of RC beams with rectangular cross-section [3], RC continuous beams [4], RC biaxial columns [5-6], RC frames [6] and RC T-beams [7]. Also, hybrid methods that combines GA with sequential quadratic programming [8], simulating annealing [9-10] and Hook and Jeeves method [11-12] were used to optimize RC members.

Harmony Search (HS) that imitates the musical performances and uses the harmony memory of musicians was also employed in many cost optimization methods for T-beams [13], slender columns [14-15], shear walls [16], frames [17-19] and retaining walls [20-21].

The number of metaheuristic-based cost optimization studies for RC members shows a great increase in the last decade and several examples are as follows.

An artificial bee colony algorithm was employed to optimize RC continuous beams by modifying the algorithm by Jahjouh et al. [22]. Nigdeli et al. [23] proposed a HS-based methodology for bi-axial loading of RC columns. Bat algorithm [24] and teaching-learningbased optimization (TLBO) [25] were employed for the optimum design of RC columns. Swarm intelligence was also used in the optimum design of RC members by Esfandiary et al. [26] and Chutani and Singh [27]. Kayabekir et al. employed the single-phase and parameterfree Jaya algorithm (JA) to optimize T-beams [28]. Also, Kayabekir et al. [29] evaluated four metaheuristics including HS, TLBO, JA, and Flower pollination algorithm (FPA) for the optimum design of RC T-beams, and Kayabekir and Nigdeli [30] statistically compared these algorithms according to methods such as one-way ANOVA, independent samples t-test, Friedman ranking, post-hoc Bonferroni test. By employing FPA, RC footings [31], RC cantilever retaining walls [32], and 3D RC frames [33] were optimized.

Generally, the objective function is the cost minimization, but optimization studies related with $\mathrm{CO}_{2}$ emission minimization have been conducted. These studies include optimization of RC frames via simulated annealing [34], RC columns via GA [35], RC frames via big-bang big crunch algorithm (BB-BC) [36], precast-prestressed concrete $U$ beam road bridges via hybrid glowworm swarm algorithm [37], post-tensioned concrete box-girders via HS [38], RC footings via BB-BC [39], RC cantilever solider piles via HS [40], RC retaining walls via HS [41], and concrete-filled steel tubular columns via spider and HS algorithms [43-43].

In the present study, the T-beam optimization is presented via FPA for $\mathrm{CO}_{2}$ minimization. The results were compared with cost optimization results ad multiple cases of cost ad $\mathrm{CO}_{2}$ ratios steel and concrete is investigated.

\section{Flower Pollination Algorithm Optimization Procedure}

The principles of the flower pollination algorithm optimization process were first introduced by Xin-She Yang in 2012 [44]. In this algorithm, Yang expressed his observations of the pollination characteristics of flowering plants with mathematical equations and then developed an algorithm including these equations to perform the optimum search process.

According to this; similar to the pollination process inspired by the algorithm, two different processes called global and local pollination are applied probabilistically in the optimization process. Global pollination is the pollination process of flowers through a carrier (such as wind, and various living things), and it is expressed in the algorithm as follows. 


$$
x_{i}^{t+1}=x_{i}^{t}+r 1 \cdot\left(x_{b}^{t}-x_{i}^{t}\right)
$$

Local pollination, on the other hand, refers to the pollination process carried out by the flower itself and was expressed by Yang as follows.

$$
x_{i}^{t+1}=x_{i}^{t}+r 2 \cdot\left(x_{j}^{t}-x_{k}^{t}\right)
$$

In the equations, $x_{i}^{t+1}$ is the new solution generated from the $x_{i}^{t}$ solution, $x_{b}^{t}$ is the best existing solution, $x_{j}^{t}$ and $x_{j}^{t}$ are two randomly selected solutions from the exiting solutions, $\mathrm{r} 1$ is the levy flight and $\mathrm{r} 2$ is a randomly generated decimal number between 0 and 1.

The application of the equations for optimum design of the reinforced concrete T-beam (Fig. 1) and processes of FPA can be summarized in five steps. The flowchart of the optimization is given as Fig. 2.

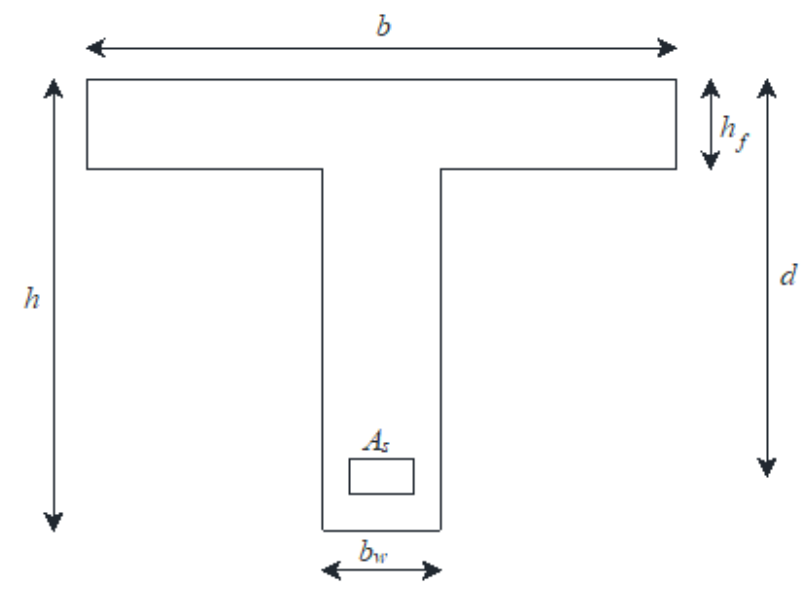

Fig. 1. Cross-section of T-shaped beam [29]

The first step is the stage where the problem is defined. At this stage, the data defined for the problem are the design constants, the lower and upper limits of the design variables, the FPA algorithm parameters, the number of solution vectors ( $\mathrm{pn}$ ), the switch probability (sp), and the maximum number of iterations as the stopping criterion. The definitions of design constants and variables and their values used in the numerical example are taken from Fedghouche and Tiliouine [7] and presented in Tables 1 and 2, respectively. The Eurocode 2 [45] regulation and the technical constraints that the section must provide are defined in Table 3.

Table 1. The design constants

\begin{tabular}{lll}
\hline Symbol & Definition & Value \\
\hline$f_{c k}$ & Characteristic compressive strength for concrete & $20 \mathrm{MPa}$ \\
$f_{c d}$ & Allowable compressive strength for concrete & $11.33 \mathrm{MPa}$ \\
$f_{y d}$ & Characteristic yield strength of reinforcement & $348 \mathrm{MPa}$ \\
$\rho_{\max }$ & The maximum reinforcement ratio & 0.04 \\
$\rho_{\min }$ & The minimum reinforcement ratio & 0.0013 \\
$L$ & The length of the beam & $20 \mathrm{~m}$ \\
$E_{s}$ & Young's elastic modules for steel & $200000 \mathrm{MPa}$ \\
$M_{E d}$ & The ultimate bending moment capacity & $4.991 \mathrm{~N} . \mathrm{m}$
\end{tabular}




$\begin{array}{lll}V_{E d} & \text { The ultimate bending moment capacity } & 1.039 \mathrm{~N} \\ C_{s} / C_{c} & \text { The ratio for unit steel and concrete costs } & 5,10,20,30,36 \\ C_{s, c o 2} / C_{c, c o 2} & \text { The ratio for unit steel and concrete costs } & 0.95,10,15,20\end{array}$

In the second step, the initial solution matrix is constructed. The design variables are generated randomly within the minimum $\left(x_{i, \min }\right)$ and maximum $\left(x_{i, \max }\right)$ ranges defined in the first step and recorded in this matrix (Eq. (3)).

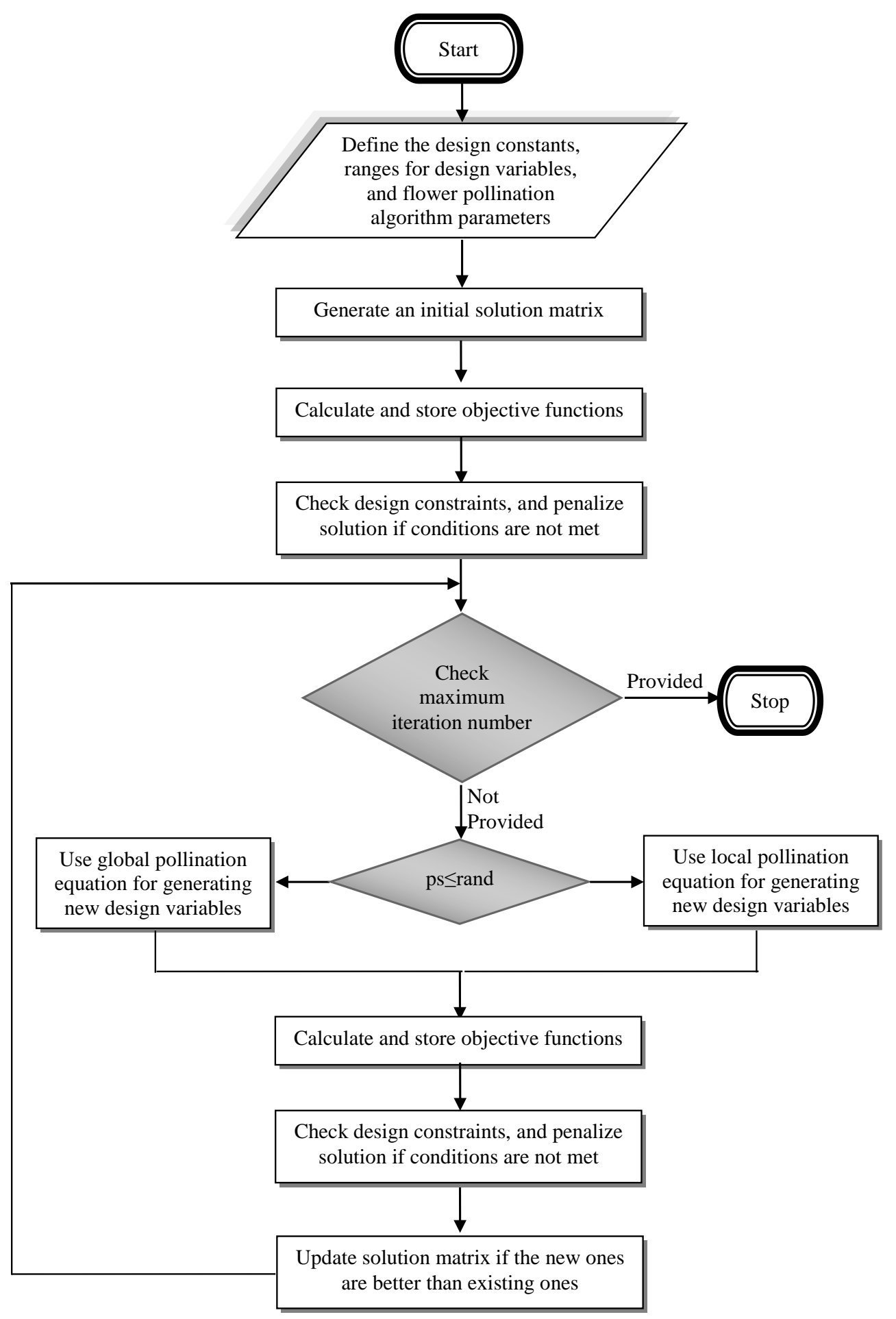


Fig. 2. Flowchart of the optimization process

$$
x_{i}=x_{i, \min }+r 3 \cdot\left(x_{i, \max }-x_{i, \min }\right)
$$

Table 2. Ranges of design variables

\begin{tabular}{llll}
\hline Symbol & Definition & Minimum & Maximum \\
\hline$b$ & Effective with of compressive flange $[\mathrm{mm}]$ & $\mathrm{b}_{\mathrm{w}}$ & $\min \left[0.2 L+b_{w}, 8 h_{f}\right]$ \\
$b_{w}$ & Web width [mm] & $0.2 \mathrm{~d}$ & $0.4 \mathrm{~d}$ \\
$h$ & Height [mm] & $\mathrm{L} / 16$ & 2.0 \\
$h_{f}$ & Flange depth [mm] & 0.15 & $\mathrm{~d}$ \\
$d$ & Effective depth [mm] & $0.9 \mathrm{~h}$ & \\
$d_{s}$ & Cover of reinforcements [mm] & $0.1 \mathrm{~h}$ & \\
$A_{s}$ & Area of reinforcing steel $\left[\mathrm{mm}^{2}\right]$ & 0 & 0.1 \\
\hline
\end{tabular}

Table 3. The design constraints

$$
\omega(1-0.5 \omega) \leq 0.392
$$$$
0.0035(0.8-\omega) / \omega \geq f_{y d} / E_{S}
$$$$
\rho_{\min } \leq \rho \leq \rho_{\max }
$$$$
M_{E d} \leq M_{E d 1}
$$$$
V_{E d} \leq V_{R d \max }
$$

After the design variables are determined, beam reinforced concrete designs are performed for each solution (from first to pn number of solutions) in the initial solution matrix. The reinforced concrete design must satisfy the Eurocode 2 [45] regulation constraints presented in Table 3 calculated based on Eqs. (4)-(9) for the situation without shear reinforcement optimization as presented in Fedghouche and Tiliouine [7].

$$
\begin{gathered}
\omega=\left(f_{y d} / f_{c d}\right)\left(A_{s} / b_{w} d\right)-\left(b-b_{w}\right) h_{f} /\left(b_{w} d\right) \\
\rho=A_{s} /\left(b_{w} d\right) \\
M_{E d 1}=f_{c d}\left(b-b_{w}\right) h_{f}\left(d-0.50 h_{f}\right)+f_{c d} b_{w} d^{2} \omega(1-0.5 \omega) \\
V_{R d \max }=v_{1} f_{c d} b_{w} z /(\tan (45)+\cot (45)) \\
v_{1}=0.6\left(1-f_{c k} / 250\right) \\
z=0.9 d
\end{gathered}
$$

Finally, in this step, the total $\mathrm{CO}_{2}$ emission value for each beam design is calculated and stored as the corresponding solution. This expression is the objective function of the optimization problem. If constraints are provided in the design, the solution is evaluated by subjecting the objective function of the design to a process called penalty. In the literature, various penalty 
methods are depending on the problem. In this study, equating the objective function to a high value $\left(10^{6}\right)$ was applied.

$$
f_{c o 2}(x)=\mathrm{C}_{c, c o 2} b_{w} d+\mathrm{C}_{c, c o 2}\left(b-b_{w}\right) h_{f}+\left(\mathrm{C}_{s, c o 2} / \mathrm{C}_{c, c o 2}\right) A_{s}
$$

For the compared cases for cost optimization, the objective function as the total beam cost is shown in Eq. (11).

$$
f_{\text {cost }}(x)=\mathrm{C}_{c} b_{w} d+\mathrm{C}_{c}\left(b-b_{w}\right) h_{f}+\left(\mathrm{C}_{s} / \mathrm{C}_{c}\right) A_{s}
$$

In the third step, the new solutions are derived. According to the algorithm rules, one of the global (Eq. (1)) or local (Eq. (2)) pollination equations is used to generate a new solution. The value of switch probability ( $\mathrm{sp}$ ) is used for the global and local pollination probabilistic selection. According to this; if the randomly generated number between 0 and 1 is less than the $\mathrm{sp}$ value, new solutions are generated according to global pollination, otherwise, local pollination rules are applied.

In the fourth step, old and new solutions are compared. The objective functions of each solution are compared, in case the new solution is better (the objective function is lower), the existing solution is deleted and the values of the new solution are saved instead. Otherwise, the existing solution is preserved.

In the last step, the stopping criterion is checked. New solution generation and comparison processes (steps 3 and 4) are repeated until the criterion is determined in the first step as the maximum number of iterations are met.

\section{Numerical Examples}

For the T-beam given in Figure 1, the analysis was carried out by the numerical values of the design constants, design constraints, and design variable limits given in Section 2. Analysis with the objective function of the total beam cost was also performed simultaneously to compare with the optimization results for $\mathrm{CO}_{2}$ emission.

As it is known, unit costs of concrete and steel vary in different parts of the world. To take this situation into account, 5 different steel and concrete unit cost ratios were taken into account in the analysis. Information on these cases is presented in Table 4.

Table 4. Cases for Cost optimization

\begin{tabular}{cccccc}
\hline Case No & 1 & 2 & 3 & 4 & 5 \\
\hline $\mathrm{C}_{\mathrm{s}} / \mathrm{C}_{\mathrm{c}}$ & 36 & 30 & 20 & 10 & 5 \\
\hline
\end{tabular}

A similar situation is seen in unit carbon emission rates. In addition to many factors such as the materials and additive rates in the concrete content and the production method, the recycled material content of the steel, even the region where the materials are produced affects the unit carbon emission rates of these materials. To take these variations into account, studies in the literature were examined and carbon emission ratios were determined for four different steel and concrete units $[34,46]$. The carbon emission rates in question are shown in Table 5. Case 6 shows the value for the use of recycled steel. 
Table 5. Cases for $\mathrm{CO}_{2}$ optimization

\begin{tabular}{ccccc}
\hline Case No & 6 & 7 & 8 & 9 \\
\hline $\mathrm{C}_{\mathrm{s}, \mathrm{co} 2} / \mathrm{C}_{\mathrm{c}, \mathrm{co} 2}$ & 0.95 & 10 & 15 & 20 \\
\hline
\end{tabular}

The optimum results for these cases are given in Tables 6 and 7. In addition to the optimum results of the design variables, the carbon emission and total cost values for the relevant cases are presented in the tables to examine the cost-carbon emission relationship.

Table 6. Optimum results for cost optimization

\begin{tabular}{crrrrr}
\hline Design variables & Case 1 & Case 2 & Case 3 & Case 4 & Case 5 \\
\hline $\mathrm{b}(\mathrm{m})$ & 1.137640 & 1.155663 & 1.229911 & 1.330057 & 1.378292 \\
$\mathrm{~b}_{\mathrm{w}}(\mathrm{m})$ & 0.304351 & 0.298164 & 0.291116 & 0.278516 & 0.272245 \\
$\mathrm{~h}(\mathrm{~m})$ & 1.690838 & 1.656469 & 1.617309 & 1.547309 & 1.512473 \\
$\mathrm{~d}(\mathrm{~m})$ & 1.521755 & 1.490822 & 1.455578 & 1.392578 & 1.361225 \\
$\mathrm{~h}_{\mathrm{f}}(\mathrm{m})$ & 0.150000 & 0.150000 & 0.153739 & 0.166323 & 0.172287 \\
$\mathrm{~A}_{\mathrm{s}}\left(\mathrm{m}^{2}\right)$ & 0.011414 & 0.011870 & 0.012071 & 0.012442 & 0.012651 \\
$\omega$ & 0.487053 & 0.530813 & 0.534350 & 0.534348 & 0.534351 \\
\hline $\mathrm{f}_{\mathrm{cost}}(\mathrm{x})$ & 0.999034 & 0.929226 & 0.809488 & 0.687166 & 0.624400 \\
\hline $\mathrm{C}_{\mathrm{s}, \mathrm{co} 2} / \mathrm{C}_{\mathrm{c}, \mathrm{co} 2}=0.95$ & 0.598984 & 0.584411 & 0.579538 & 0.574569 & 0.573162 \\
$\mathrm{C}_{\mathrm{s}, \mathrm{co} 2} / \mathrm{C}_{\mathrm{c}, \mathrm{co} 2}=10$ & 0.702278 & 0.691832 & 0.688780 & 0.687166 & 0.687656 \\
$\mathrm{C}_{\mathrm{s}, \mathrm{co} 2} / \mathrm{C}_{\mathrm{c}, \mathrm{co} 2}=15$ & 0.759346 & 0.751180 & 0.749134 & 0.749375 & 0.750912 \\
$\mathrm{C}_{\mathrm{s}, \mathrm{co} 2} / \mathrm{C}_{\mathrm{c}, \mathrm{co} 2}=20$ & 0.827828 & 0.822398 & 0.821559 & 0.824025 & 0.826819 \\
\hline
\end{tabular}

Table7. Optimum results for $\mathrm{CO}_{2}$ optimization

\begin{tabular}{crrrr}
\hline Design variables & Case 6 & Case 7 & Case 8 & Case 9 \\
\hline $\mathrm{b}(\mathrm{m})$ & 1.382218 & 1.327519 & 1.278476 & 1.217860 \\
$\mathrm{~b}_{\mathrm{w}}(\mathrm{m})$ & 0.271727 & 0.278872 & 0.285113 & 0.292575 \\
$\mathrm{~h}(\mathrm{~m})$ & 1.509592 & 1.549286 & 1.583961 & 1.625415 \\
$\mathrm{~d}(\mathrm{~m})$ & 1.358633 & 1.394358 & 1.425565 & 1.462873 \\
$\mathrm{~h}_{\mathrm{f}}(\mathrm{m})$ & 0.172777 & 0.165940 & 0.159810 & 0.152232 \\
$\mathrm{~A}_{\mathrm{s}}\left(\mathrm{m}^{2}\right)$ & 0.012669 & 0.012430 & 0.012239 & 0.012032 \\
$\omega$ & 0.534351 & 0.534351 & 0.534345 & 0.534351 \\
\hline $\mathrm{f}_{\mathrm{co} 2}(\mathrm{x})$ & 0.573080 & 0.687161 & 0.748787 & 0.821529 \\
\hline $\mathrm{C}_{\mathrm{s}} / \mathrm{C}_{\mathrm{c}}=5$ & 0.624391 & 0.625010 & 0.626393 & 0.629018 \\
$\mathrm{C}_{\mathrm{s}} / \mathrm{C}_{\mathrm{c}}=10$ & 0.687737 & 0.687161 & 0.687590 & 0.689178 \\
$\mathrm{C}_{\mathrm{s}} / \mathrm{C}_{\mathrm{c}}=20$ & 0.814431 & 0.811463 & 0.809984 & 0.809497
\end{tabular}




$\begin{array}{lllll}\mathrm{C}_{\mathrm{s}} / \mathrm{C}_{\mathrm{c}}=30 & 0.941124 & 0.935765 & 0.932378 & 0.929817 \\ \mathrm{C}_{\mathrm{s}} / \mathrm{C}_{\mathrm{c}}=36 & 1.01714 & 1.010347 & 1.005815 & 1.002009\end{array}$

\section{Discussion of The Results}

As seen in Fig. 3, by the increase of the cost of steel bars concerning the cost of concrete, the cross-section dimensions are increasing in size for $\mathrm{b}_{\mathrm{w}}, \mathrm{h}_{\mathrm{f}}$, and $\mathrm{d}$. In that case, the area of rebar is approximately reduced by $1 \mathrm{dm}^{2}$. The increase in the flange of the beam also results in the increase of rebar for equilibrium. In that case, $h$ is optimally chosen to be increased to reduce the amount of rebar that has a high cost. The optimization methodology can decide it and it shows a relationship with the theory of RC design.

As seen from Fig. 3, the reduction of cost ratio of steel per column reduces the total optimum cost. For Case 1 to 5, a significant difference for $\mathrm{CO}_{2}$ emission is not seen if $\mathrm{C}_{\mathrm{s}, \mathrm{co} 2} / \mathrm{C}_{\mathrm{c}, \mathrm{co} 2}$ is bigger than 10, but the $\mathrm{CO}_{2}$ emission for Case 5 is $4.5 \%$ better than Case 1 if $\mathrm{C}_{\mathrm{s}, \mathrm{co} 2} / \mathrm{C}_{\mathrm{c}, \mathrm{co} 2}=0.95$.

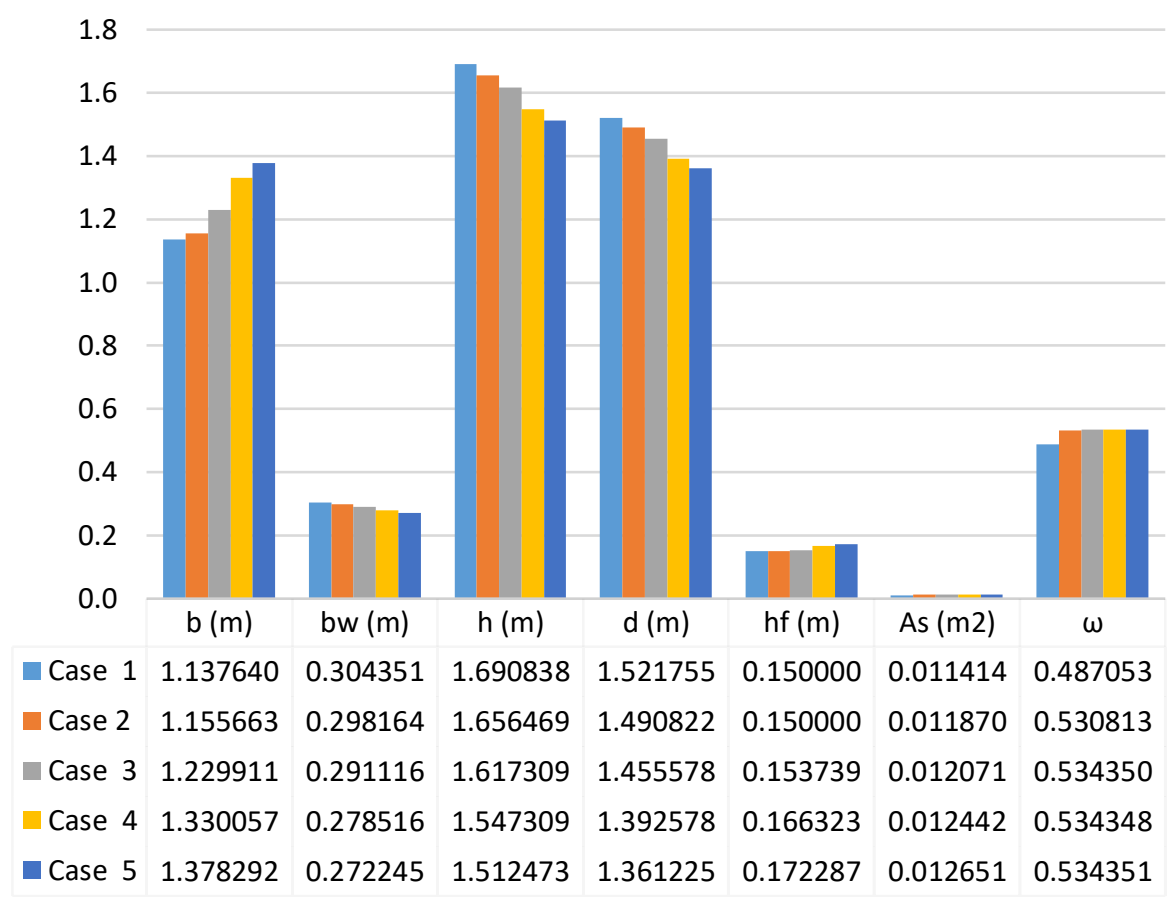

Fig. 3. Design variables for the cost optimization

As seen in Fig. 5, the increase of $\mathrm{C}_{\mathrm{s}, \mathrm{co} 2} / \mathrm{C}_{\mathrm{c}, \mathrm{co} 2}$ shows the same increases and decreases as cost optimization for the cross-section dimensions. Fig. 6 shows the $\mathrm{CO}_{2}$ emission and cost concerning different cost ratios. In $\mathrm{CO}_{2}$ minimization, it is possible to find solutions with lower $\mathrm{CO}_{2}$ emissions than the results found via cost optimization. For cost optimization results of Case 5, the gap between $\mathrm{CO}_{2}$ values for cost and $\mathrm{CO}_{2}$ optimization closes.

In $\mathrm{CO}_{2}$ optimization, Case 6 has a marginal $\mathrm{C}_{\mathrm{s}, \mathrm{co} 2} / \mathrm{C}_{\mathrm{c}, \mathrm{co} 2}$ ratio that can reflect a case of using recycled steel. In this case, the dimensions of $b$ and $h_{f}$ are the biggest compared to all cases. In Case 9, the costs are close to cost optimization results. This proves that cost and $\mathrm{CO}_{2}$ 
optimization may have very different optimum results if $\mathrm{C}_{\mathrm{s}, \mathrm{co} 2} / \mathrm{C}_{\mathrm{c}, \mathrm{co} 2}$, and $\mathrm{C}_{\mathrm{s}} / \mathrm{C}_{\mathrm{c}}$ are different. The use of recycled steel is $30.24 \%$ more eco-friendly comparing to Case 9 .

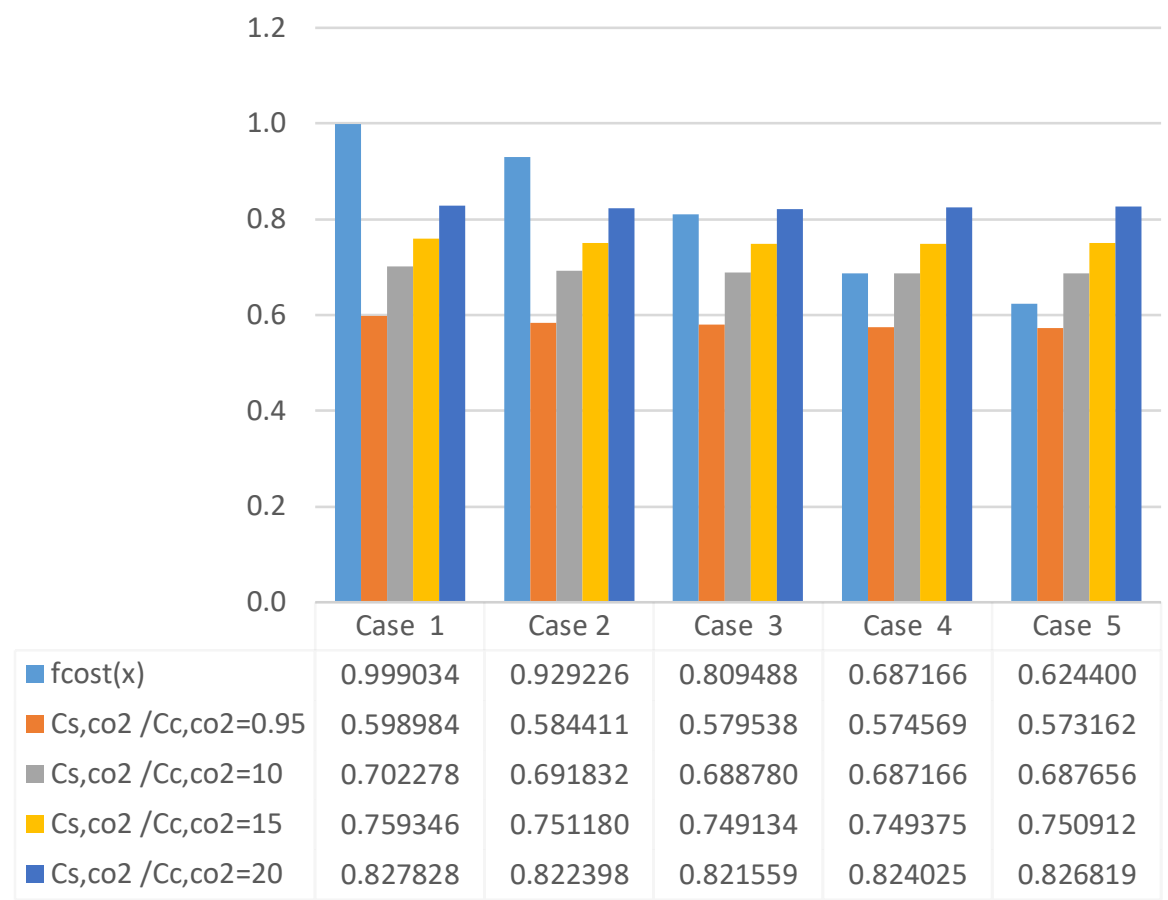

Fig. 4. Objective functions for cost optimization

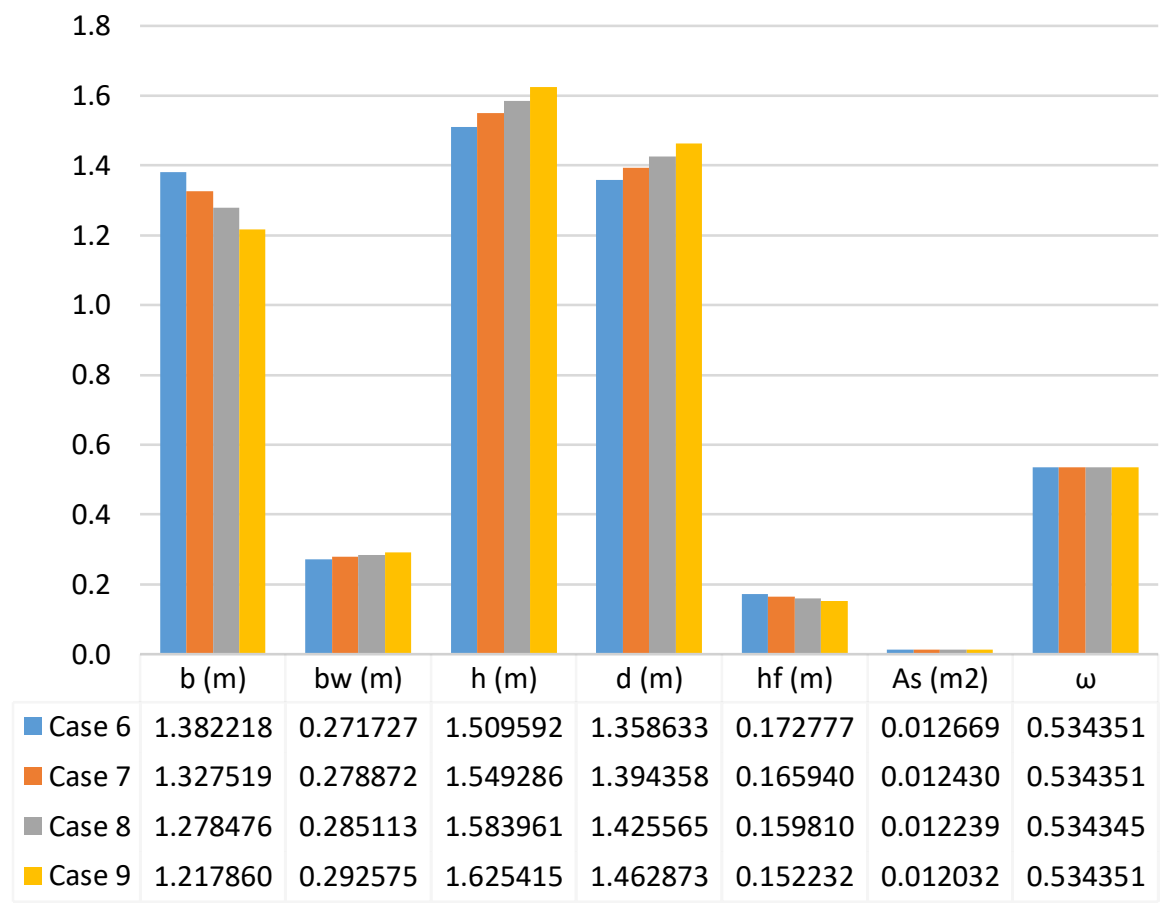

Fig. 5. Design variables for the $\mathrm{CO}_{2}$ optimization 


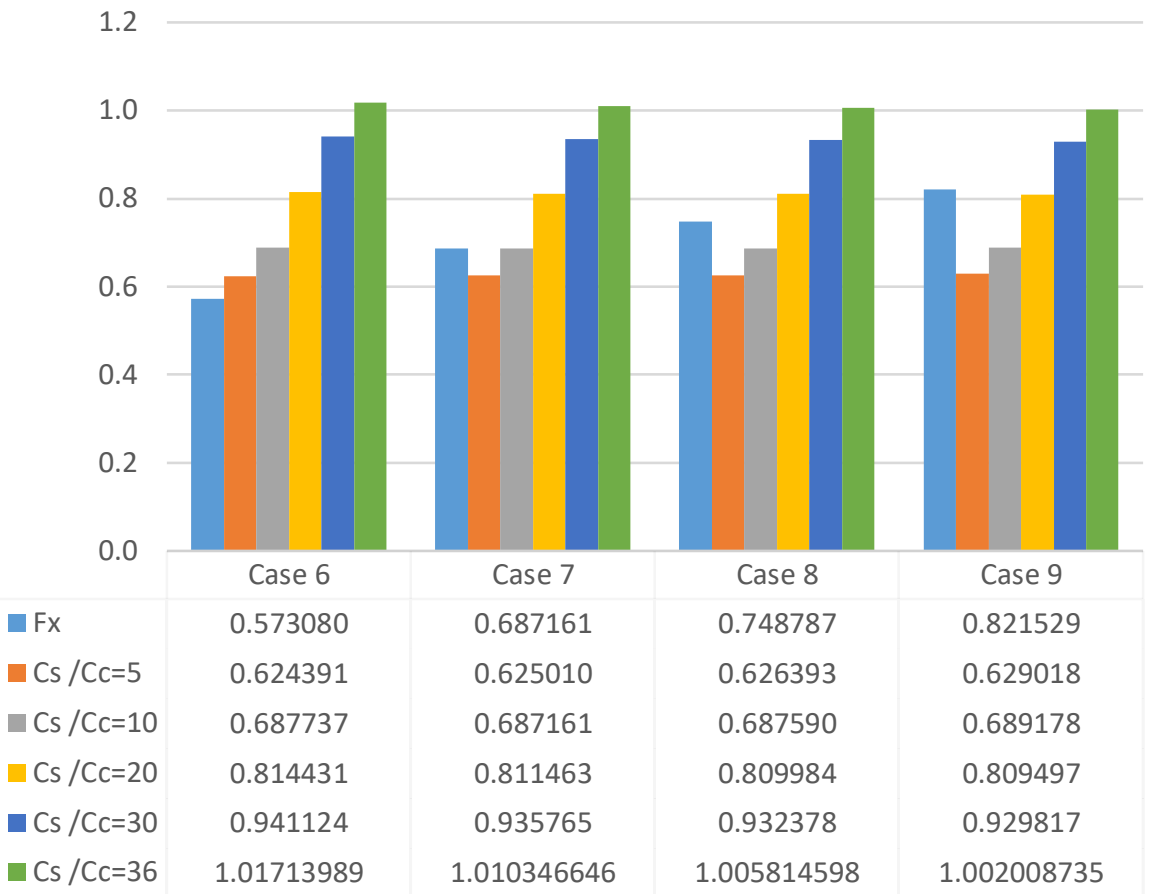

Fig. 6. Objective functions for the $\mathrm{CO}_{2}$ optimization

\section{Conclusion}

In the present paper, an optimization methodology for the $\mathrm{CO}_{2}$ emission minimization of $\mathrm{T}$ beams is presented. To find out the differences between $\mathrm{CO}_{2}$ and cost optimization, both objectives are calculated for multiple cases of cost and $\mathrm{CO}_{2}$ emission ratios of steel and concrete. According to the results, the cross-section dimensions ad steel reinforcement area shows great differences for these ratios. For both increases of cost and $\mathrm{CO}_{2}$ emission of steel, the optimum design tends to be minimum in reinforcement area and maximum in the moment arm value by increasing the height and directly increasing the depth of T-beam.

Since the cost and $\mathrm{CO}_{2}$ objectives are similar in form with the only difference in cost and $\mathrm{CO}_{2}$ values of the materials, the behavior is the same in $\mathrm{CO}_{2}$ and cost optimization. Due to that, the difference in $\mathrm{CO}_{2}$ values for cost and $\mathrm{CO}_{2}$ optimization are close if cost and $\mathrm{CO}_{2}$ ratios of steel per concrete are similar as seen from the results of Case 3 and Case 9 or Case 4 and Case 7. This is not acceptable for Case 6 where recycled steel bars are used. This case has $4.5 \%$ reduced $\mathrm{CO}_{2}$ emission concerning cost optimization and $30.24 \%$ reduced $\mathrm{CO}_{2}$ emission compared to Case 9 .

As the final remarks, $\mathrm{CO}_{2}$ optimization may have different optimum results if $\mathrm{C}_{\mathrm{s}} / \mathrm{C}_{\mathrm{c}}$ and $\mathrm{C}_{\mathrm{s}, \mathrm{co} 2} /$ $\mathrm{C}_{\mathrm{c}, \mathrm{co} 2}$ are different. Also, recycled steel is very useful in the protection of the earth by conducting an optimum design.

\section{References}

[1] Goldberg, D.E.: Genetic algorithms in search, Optimization and machine learning. Boston MA: Addison Wesley, 1989. 
[2] Holland, J.H.: Adaptation in Natural and Artificial Systems. Ann Arbor MI: University of Michigan Press, 1975.

[3] Coello, C. C., Hernández, F. S., Farrera, F. A., Optimal design of reinforced concrete beams using genetic algorithms. Expert systems with Applications, 12(1), 101-108, 1997.

[4] Koumousis, V. K., \& Arsenis, S. J., Genetic algorithms in optimal detailed design of reinforced concrete members. Computer-Aided Civil and Infrastructure Engineering, 13(1), 43-52, 1998.

[5] Rafiq, M. Y., \& Southcombe, C., Genetic algorithms in optimal design and detailing of reinforced concrete biaxial columns supported by a declarative approach for capacity checking. Computers \& Structures, 69(4), 443-457, 1998.

[6] Camp, C. V., Pezeshk, S., \& Hansson, H., Flexural design of reinforced concrete frames using a genetic algorithm. Journal of Structural Engineering, 129(1), 105-115, 2003.

[7] Fedghouche, F., \& Tiliouine, B., Minimum cost design of reinforced concrete T-beams at ultimate loads using Eurocode2. Engineering Structures, 42, 43-50, 2012

[8] Rath, D. P., Ahlawat, A. S., \& Ramaswamy, A., Shape optimization of RC flexural members. Journal of Structural Engineering, 125(12), 1439-1446, 1999.

[9] Govindaraj, V., \& Ramasamy, J. V., Optimum detailed design of reinforced concrete continuous beams using genetic algorithms. Computers \& structures, 84(1-2), 34-48, 2005.

[10] Lepš, M., \& Šejnoha, M., New approach to optimization of reinforced concrete beams. Computers \& structures, 81(18-19), 1957-1966, 2003.

[11] Sahab, M. G., Ashour, A. F., \& Toropov, V. V., A hybrid genetic algorithm for reinforced concrete flat slab buildings. Computers \& structures, 83(8-9), 551-559, 2005.

[12] Sahab, M. G., Ashour, A. F., \& Toropov, V. V., Cost optimisation of reinforced concrete flat slab buildings. Engineering Structures, 27(3), 313-322, 2005.

[13] Bekdaş, G., \& Nigdeli, S. M., Optimization of T-shaped RC flexural members for different compressive strengths of concrete. International Journal of Mechanics, 7, 109-119, 2013.

[14] Bekdas, G., \& Nigdeli, S. M., The optimization of slender reinforced concrete columns. PAMM, 14(1), 183-184, 2014.

[15] Bekdaş G., \& Nigdeli S.M., The Effect of Eccentricity for Optimum Compressively Loaded Reinforced Concrete Column. In 15th EU/ME Workshop: Metaheuristic and Engineering, Istanbul, Turkey, 2014.

[16] Nigdeli S.M., \& Bekdaş G., Optimization of reinforced concrete shear walls using harmony search. In 11th International Congress on Advances in Civil Engineering, Istanbul, Turkey, 2014.

[17] Akin, A., \& Saka, M. P., Harmony search algorithm based optimum detailed design of reinforced concrete plane frames subject to ACI 318-05 provisions. Computers \& Structures, 147, 79-95, 2015.

[18] Bekdaş G., \& Nigdeli S.M., Optimization of RC Frame Structures Subjected to Static Loading. 11th. World Congress on Computational Mechanics, Barcelona, Spain, 2014. 
[19] Ulusoy S., Kayabekir A.E., Bekdaş G., \& Nigdeli S.M., Optimum Design of Reinforced Concrete Multi-Story Multi-Span Frame Structures under Static Loads. In 8th International Conference on Environment Science and Engineering (ICESE 2018), Barcelona, Spain, 2018.

[20] Akin, A. \& Saka, M.P., Optimum Detailed Design of Reinforced Concrete Continuous Beams using the Harmony Search Algorithm, In The Tenth International Conference on Computational Structures Technology, Paper 131, Stirlingshire, UK, 2010.

[21] Kayabekir, A. E., Arama, Z. A., \& Bekdas, G., Effect of application factors on optimum design of reinforced concrete retaining systems. Structural Engineering and Mechanics, 80(2), 113-127, 2021.

[22] Jahjouh, M. M., Arafa, M. H., \& Alqedra, M. A., Artificial Bee Colony (ABC) algorithm in the design optimization of RC continuous beams. Structural and Multidisciplinary Optimization, 47(6), 963-979, 2013.

[23] Nigdeli, S. M., Bekdas, G., Kim, S., \& Geem, Z. W., A novel harmony search based optimization of reinforced concrete biaxially loaded columns. Structural Engineering and Mechanics, 54(6), 1097-1109, 2015.

[24] Bekdaş G., \& Nigdeli S.M., Bat algorithm for optimization of reinforced concrete columns. In Joint Annual Meeting of GAMM and DMV, Braunschweig, Germany, 2016.

[25] Bekdaş G., \& Nigdeli S.M., Optimum Design Of Reinforced Concrete Columns Employing Teaching Learning Based Optimization. In 12th International Congress on Advances in Civil Engineering, Istanbul, Turkey, 2016.

[26] Esfandiary, M. J., Sheikholarefin, S., \& Bondarabadi, H. R., A combination of particle swarm optimization and multi-criterion decision-making for optimum design of reinforced concrete frames. International Journal of Optimization in Civil Engineering, 6(2), 245-268, 2016.

[27] Chutani, S., \& Singh, J., Use of modified hybrid PSOGSA for optimum design of RC frame. Journal of the Chinese Institute of Engineers, 41(4), 342-352, 2018.

[28] A. E. Kayabekir, G. Bekdaş and S. M. Nigdeli, Optimum Design of T-Beams Using Jaya Algorithm in 3rd International Conference on Engineering Technology and Innovation (ICETI), Belgrad, Serbia, 2019.

[29] Kayabekir, AE, Bekdaş G, Nigdeli SM. Evaluation of Metaheuristic Algorithm on Optimum Design of T-Beams, 6th International Conference on Harmony Search, Soft Computing and Applications (ICHSA 2020), 16-17 July 2020, Istanbul, Turkey.

[30] Kayabekir, A. E., \& Nigdeli, M., Statistical Evaluation of Metaheuristic Algorithm: An Optimum Reinforced Concrete T-beam Problem. In Advances in Structural EngineeringOptimization 299-310. Springer, Cham, 2021.

[31] Nigdeli, Sinan Melih, Gebrail Bekdaş, and Xin-She Yang. Metaheuristic optimization of reinforced concrete footings. KSCE Journal of Civil Engineering, 22.11(2018), 4555-4563, 2018.

[32] Mergos, P. E., \& Mantoglou, F., Optimum design of reinforced concrete retaining walls with the flower pollination algorithm. Structural and Multidisciplinary Optimization, 61(2), 575-585, 2020. 
[33] Mergos, P. E., Optimum design of 3D reinforced concrete building frames with the flower pollination algorithm. Journal of Building Engineering, 44, 102935, 2021.

[34] Paya-Zaforteza, I., Yepes, V., Hospitaler, A., \& Gonzalez-Vidosa, F., CO2-optimization of reinforced concrete frames by simulated annealing. Engineering Structures, 31(7), 15011508, 2009.

[35] Park, H. S., Kwon, B., Shin, Y., Kim, Y., Hong, T., \& Choi, S. W., Cost and CO2 emission optimization of steel reinforced concrete columns in high-rise buildings. Energies, 6(11), 5609-5624, 2013.

[36] Camp, C. V., \& Huq, F., CO2 and cost optimization of reinforced concrete frames using a big bang-big crunch algorithm. Engineering Structures, 48, 363-372, 2013.

[37] Yepes, Víctor, José V. Martí, and Tatiana García-Segura. Cost and CO2 emission optimization of precast-prestressed concrete U-beam road bridges by a hybrid glowworm swarm algorithm. Automation in Construction, 49 (2015), 123-134, 2015.

[38] García-Segura, T., Víctor Y., Multiobjective optimization of post-tensioned concrete boxgirder road bridges considering cost, $\mathrm{CO} 2$ emissions, and safety. Engineering Structures, 125 (2016): 325-336, 2016.

[39] Camp, C. V., and Andrew, A., CO2 and cost optimization of reinforced concrete footings subjected to uniaxial uplift. Journal of Building Engineering, 3 (2015), 171-183, 2015.

[40] Arama, Z. A., Kayabekir, A. E., Bekdaş, G., \& Geem, Z. W., CO2 and cost optimization of reinforced concrete cantilever soldier piles: a parametric study with harmony search algorithm. Sustainability, 12(15), 5906, 2020.

[41] Kayabekir, A. E., Arama, Z. A., Bekdaş, G., Nigdeli, S. M., \& Geem, Z. W., Eco-friendly design of reinforced concrete retaining walls: multi-objective optimization with harmony search applications. Sustainability, 12(15), 6087, 2020.

[42] Cakiroglu, C., Islam, K., Bekdaş, G., \& Billah, M., CO2 Emission and Cost Optimization of Concrete-Filled Steel Tubular (CFST) Columns Using Metaheuristic Algorithms. Sustainability, 13(14), 8092, 2021.

[43] Cakiroglu, C., Islam, K., Bekdaş, G., Kim, S., \& Geem, Z. W., CO2 Emission Optimization of Concrete-Filled Steel Tubular Rectangular Stub Columns Using Metaheuristic Algorithms. Sustainability, 13(19), 10981, 2021

[44] Yang, X. S. Flower pollination algorithm for global optimization. In International conference on unconventional computing and natural computation, Springer, Berlin, Heidelberg. 240-249, 2012

[45] EN (Veranst.): EN 1992-1-1 Eurocode 2: Design of concrete structures. Brussels : CEN, 2005

[46] Yeo, Dong Hun, and Florian A. Potra. Sustainable design of reinforced concrete structures through $\mathrm{CO}_{2}$ emission optimization. Journal of Structural Engineering, 141(3), B4014002, 2015 . 